\title{
Managing environmental building performance through IT systems
}

\author{
Maslesa, Esmir; Jensen, Per Anker
}

Published in:

Facilities

Link to article, DOI:

10.1108/f-01-2019-0013

Publication date:

2019

Document Version

Peer reviewed version

Link back to DTU Orbit

Citation (APA):

Maslesa, E., \& Jensen, P. A. (2019). Managing environmental building performance through IT systems. Facilities, 38(3/4), 235-251. https://doi.org/10.1108/f-01-2019-0013

\section{General rights}

Copyright and moral rights for the publications made accessible in the public portal are retained by the authors and/or other copyright owners and it is a condition of accessing publications that users recognise and abide by the legal requirements associated with these rights.

- Users may download and print one copy of any publication from the public portal for the purpose of private study or research.

- You may not further distribute the material or use it for any profit-making activity or commercial gain

- You may freely distribute the URL identifying the publication in the public portal

If you believe that this document breaches copyright please contact us providing details, and we will remove access to the work immediately and investigate your claim. 


\title{
Managing environmental building performance through IT systems
}

\author{
Esmir Maslesa and Per Anker Jensen \\ Department of Management, \\ Technical University of Denmark,
}

\begin{abstract}
Purpose: The paper aims to disclose the role and features of various IT systems for environmental building performance (EBP) in facilities management.

Design: The research focuses on IT systems used for real estate and facilities management in four organisations. The research is based on a maximum variance case study in which the selected organisations have different organisation type and portfolio size. Three organisations are from Denmark and one is from United Kingdom.

Findings: Several IT systems can be used for managing EBP. EBP in IT systems is primarily reflected through energy management, with specific focus on monitoring and reporting electricity, heating and water consumption. Furthermore, greenhouse gas emissions related to energy consumption can be calculated in some IT systems, while other environmental categories like building materials and recycling potentials are not adequately supported by the systems covered in this study. Some IT systems offer additional features relating to EBP, such as waste management and space management, but the study shows that these features are not demanded by the case organisations at the current point.

Practical implications: The results can be used to support decision-making in organisations to improve the environmental building performance in facilities management by IT systems.

Originality/value: This research contributes with new knowledge on how IT systems are used in different organisations for managing EBP. The paper also shows how various IT systems can add value to real estate organisations and facilities management departments and support their business processes relating to EBP.
\end{abstract}

Keywords: Environmental building performance, Sustainability, IT system, IWMS, EMS, BMS

Article type: Research paper 


\section{Sustainability and environmental building performance}

Sustainable buildings, green buildings, smart buildings. Nowadays many terms try to communicate that some buildings are better performing than others, when it comes to their environmental sustainability. Yet, statistics show that the buildings and building construction sector combined consume $36 \%$ of global energy consumption and induce nearly $40 \%$ of total $\mathrm{CO}_{2}$ emissions (International Energy Agency, 2017). Moreover, a deeper look at buildings' environmental performance in a life cycle perspective shows that the use stage of older buildings is typically responsible for $80-90 \%$ of environmental impacts, while newer, more "sustainable" buildings have lower operational impacts at the expense of higher embodied impacts during building construction indicating burden shifting tendencies between life cycle stages (Sharma et al., 2011; Cabeza et al., 2014).

Assessing sustainability in buildings is not an easy task and must include all three dimensions (economic, environmental and social) of sustainability. This paper is particularly focusing on the environmental dimension of sustainability and therefore uses the term "environmental building performance" (EBP) to address environmental impacts induced during buildings' operation and maintenance activities. Managing EBP is a complex task since EBP includes several categories that are interrelated. A systematic literature review by Maslesa et al. (2018) identified eight environmental categories that should be considered when managing EBP: energy management, water management, emissions, space management, waste management, building materials, indoor environmental quality, and recycling potential. However, the same study also discovered that the identified environmental categories are not equally represented in research, and that especially energy management and greenhouse gas $(\mathrm{GHG})$ emissions are in focus.

There are various IT systems available for managing EBP in facilities management, but there is a lack of knowledge on how they are used, what their strengths and weaknesses are, and how adequately they cover previously identified environmental categories. Thus, there is a need for further studies within this field. For this paper, we have formulated the following research question: How is environmental building performance managed through various IT systems, and are there any gaps between theoretical environmental indicators and those used in practice?

The literature search within peer-reviewed research papers on the relationship between environmental building performance and IT systems shows limited research on this topic. Relevant studies of IT systems in Real Estate Management (REM) and Facilities Management (FM) have earlier been conducted by Elmualim and Pelumi-Johnson (2009), Lewis et al. (2010), Gibler et al. (2010), and Ebbesen (2015), but they lack a more comprehensive focus on management of EBP through IT systems. Our paper aims to provide new knowledge on this research topic by answering the above research question.

In the paper, FM is used as the general term for the business area in scope, which also includes the related and overlapping area of REM. 


\section{IT in Facilities Management}

\subsection{Information and knowledge management}

FM has evolved over time which can be attributed to several important factors from three thematic groupings: i) business environment - including organisational structure, business objectives, and company culture and contextual issues, ii) buildings and facilities characteristics - for example, facility type, location and size, and iii) external interventions/factors - such as business needs and processes, asset maintenance priorities, legislation, and interrelationships with other contractors (Pärn et al. 2017). Thus, accurate, reliable and ubiquitous information is vital for supporting efficient FM. However, the FM sector continues to struggle with information management, mostly due to the peculiarity of information and its fragmentation (Eastman et al., 2008; Pärn et al., 2017). IT systems are therefore needed to manage and consolidate the data and information necessary to make decisions about how to operate and maintain buildings (Lewis et al., 2010).

It is important to distinguish between data, information and knowledge. A collection of data is not information, and a collection of information is not knowledge. Collection of data and information are not usable knowledge, but just collections. Information can be portrayed as the transformation of data, and knowledge as the transformation of information. Therefore, Knowledge Management (KM) can be described as a strategy that aims to develop organisational knowledge through accumulation of organisational data and information, along with past experiences derived from human resources (Dubey and Kalwale, 2010).

The rapid digitisation is one of the crucial reasons why increased access to knowledge has become possible. There are two different types of knowledge: explicit and tacit (Heisig, 2009; McBeath and Ball, 2012). The explicit knowledge of an organisation is systematic and can easily be codified, distributed and reused. Tacit knowledge is nonarticulated knowledge based on individual experiences and personal beliefs, values and perspectives (Pan and Scarbrough, 1999; Vianello and AhmedKristensen, 2012). Thus, tacit knowledge is difficult to extract, formalise, share and transfer (Lundvall, 2004). Information technology (IT) systems do not transfer knowledge on its own but rely on the people using it. However, Alvesson and Kärreman (2001) highlight IT systems as an important symbol for KM as they communicate to the employees, that in the company, knowledge is shared.

Within the research field of FM, KM has only been researched to a limited extent. One of the first studies by Pathirage et al. (2008) related KM to Intellectual Capital, which they divided in three components: Human Capital, Structural Capital and Customer Capital. The Structural Capital describes the internal structure of an organisation comprising strategy, operating system, physical resources, and work processes of a FM business. The study developed a maturity model of KM in FM with four stages: I) Recognition of importance, II) Formulation of strategy, III) Implementation of techniques, and IV) Evaluation of performance.

$\mathrm{KM}$ is a key source in improving organisational performance (Mutalib et al., 2018). Acquisition of new knowledge is followed by its codification. Codification mechanisms ensure that the new knowledge becomes part of the organisational memory, expanding its reusability in order to deal with future issues similar to past issues as well as link individuals with beneficial knowledge. IT has a crucial role in the acquirement and codification of organisational knowledge as it can store large amounts of knowledge, allowing its smooth distribution and re-use. Therefore, a robust IT 
infrastructure to support both the codification and storage of the organisational knowledge is essential. The selection of appropriate technology should be aligned with different organisational aspects. The most important aspect is organisational culture as it is the one that affects internal communication and knowledge transfer, with operational, technical and cost aspects being significant as well (Smith, 2001). The use of IT systems for KM is related to the third stage of implementation of techniques in the KM maturity model by Pathirage et al. (2008). IT systems are essential knowledge repositories for codified knowledge (Davenport et al., 1998).

\subsection{IT systems and technologies in FM: overview}

Facilities are operated at three management levels: strategic, tactical and operational level. This requires capturing and combining different datasets that can help to calculate building performance, operational costs, environmental impacts etc. To do all of this, facilities managers and other decision makers must have the necessary data and information systems in place to support their decisions (Barkley, 2001). Digitisation of the FM sector started two-three decades ago, focusing on the operational and tactical level to solve specific FM tasks through IT systems. Later, FM middle management started supporting digitisation as they realised the value of workflow outputs. In the past decade, top management began to see strategic benefits of digitisation within FM, especially concerning management information needed for future strategic reporting and planning (DFM, 2018a).

Nowadays, IT systems and technologies in FM can be grouped in seven categories, as illustrated in Figure 1 (Ebbesen, 2016). Categories like workflow systems and facilities intelligence systems relate directly to IT systems, while other categories cover technologies and data related to the systems. There is often a strong relationship and dependency across different categories in a FM organisation. For example, workflow systems require input data from data repositories to work properly, and in relation to that, an appropriate interface between the systems and databases must be developed, based on certain exchange standards and protocols.

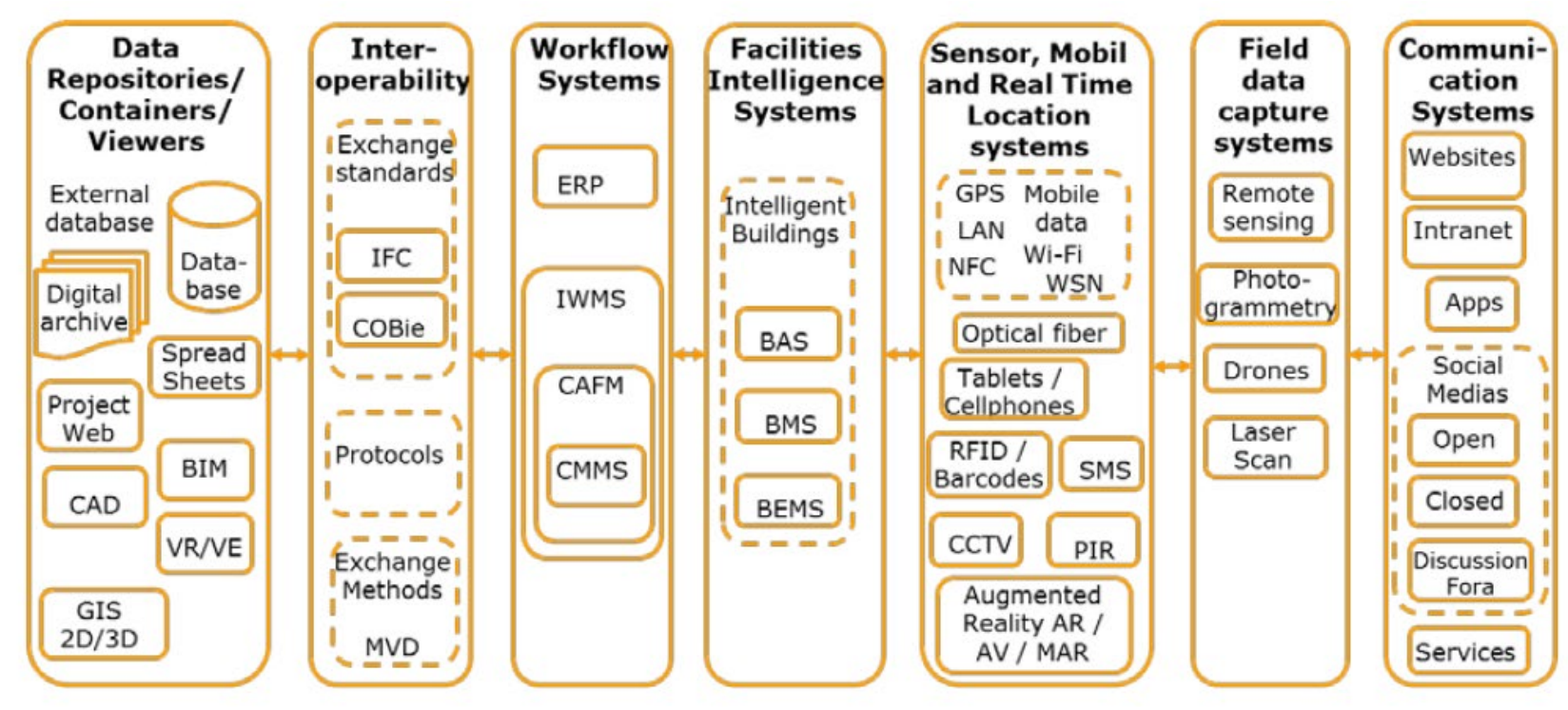

Figure 1: IT systems and technologies in FM (Ebbesen, 2016). 
IT systems covered in this research are "workflow systems" and "facilities intelligence systems" since they are primarily used for managing EBP. Workflow systems are, as the name indicates, used for digitising the workflows/business processes related to FM. There are several types of workflow systems in FM, including: Computerised Maintenance Management System (CMMS), Computer Aided Facilities Management (CAFM), Integrated Workplace Management System (IWMS), and Enterprise Resource Planning (ERP).

The core function of a CMMS is to manage information related to maintenance, including but not limited to work orders, asset histories, parts inventories, maintenance personnel management and the calculation of maintenance metrics (Lewis et al., 2010).

CAFM is a tool for organising and managing various activities within the facilities assets and ranges from a simple space management tool to a range of applications such as: maintenance and operations, budgeting and accounting, construction and project management, space forecasting, lease and property management, and asset management (Elmualim and Pelumi-Johnson, 2009).

IWMS addresses a wide range of management needs: financial and lease management, facilities management, space management, project management, and environmental sustainability (Trimble, 2018). IWMS is in research often perceived as, or similar to CAFM (Madritsch and May, 2009; Pärn et al., 2017), while Danish FM practitioners consider IWMS as the most complex IT system that includes functionalities from CMMS and CAFM (DFM, 2018b). Unlike traditional databases, IWMS operates with associative datasets, meaning that a work task is linked to records for the associated employee, assets and procedures. Thus, the implementation of IWMS requires to set-up the organisational portfolio records, with resources such as people, locations (sites, buildings, floors and spaces), assets, organisational hierarchies, and cost codes (Hanley and Brake, 2016). IWMS is sometimes also associated with an ERP. An ERP can be used across an entire organisation to manage all types of information, including corporate finance, human resources, procurement and the functions of CAFM and CMMS. ERP can also be used for energy performance monitoring and benchmarking (Lewis et al., 2010).

Facilities intelligence systems, on the other hand, focus on the actual performance of buildings and their technical installations. Most commonly known facilities intelligence systems are Building Automation System (BAS), Building Management System (BMS) and Building Energy Management System (BEMS/EMS) (Ebbesen, 2016). They are used to monitor, control and manage heating, ventilation, air conditioning (HVAC) and electrical systems in buildings. Their core function is to maintain adequate indoor environmental conditions such as temperature and relative humidity during building operation hours (Lewis et al., 2010).

In this paper, we distinguish between BMS (in Danish CTS) and EMS as they are used for different purposes within energy management. BMS is defined as a system used for digital monitoring, control and management of HVAC and electrical systems in buildings. EMS is a system used to monitor and manage energy and water consumption within buildings. Both BMS and EMS are considered as single point systems as they only relate to one specific business area, in this case energy management. 


\subsection{Drivers and success factors}

Many influential factors from business environment determine the organisation's needs for IT systems. Gibler et al. (2010) found that organisations buy new IT systems for many reasons, but some of the most important include reducing transaction costs, reducing errors, enabling information sharing, formalizing business processes, and increasing processing speed.

García-Sánchez and Pérez-Bernal (2007) found that most of the critical success factors in implementing IT systems were not technical, but included leadership, training, communication, and cooperation. These findings were also supported by a CAFM market survey (GEFMA 940, 2017), which showed that $35 \%$ of the implementation costs were direct software acquisition costs, while the remaining $65 \%$ were costs associated with data capture and migration, and customisation and user training.

The GEFMA survey showed that the implementation process and the user training are just as important as the software. Also Hanley and Brake (2016) emphasised that the most successful IT implementation depended on a pace of change that the organisation and its people could support, meaning that business process and data governance needed a step change to evolve with the new technology. The difference between successful and unsuccessful implementation seems to be planning, expectation setting and managing the change within the organization more than the quality of any one software vendor (Gibler et al., 2010). Gibler et al. (2010) claim that some real estate department implemented IWMS with excellent results and return on investment (ROI), while other, similar organisations failed in the end due to problems ranging from poor planning to lack of executive business sponsorship and mandate to oversold software and ineffective implementation teams.

Prischl et al. (2012) present a method to demonstrate the economic benefits of CAFM implementation based on the concept of ROI drivers. They divide ROI drivers into two groups; (1) ROI drivers that represent and affect typical FM processes such as contract management, maintenance management, portfolio management, and vacancy management; (2) ROI drivers that represent process-independent economic potential, such as transparency, standardization, and the contribution to Corporate Identity. The ROI drivers can have impact on real estate cost, income and asset value. They are measured by a combination of Economic Added Value (EVA = ROI divided by weighted capital cost) and time rate of the return from slow (3-5 years), medium (12 month) to fast (1 month). The results are illustrated in a diagram, where the rate is the x-axis, EVA is the y-axis, and circles placed in the diagram with different diameters represent the potential of the ROI drivers as low, medium or big. The examples in Prischl et al. (2012) include Energy and Environmental Management - also called Utilities Management - but this is regarded as the areas with the lowest potential with medium to low EVA and medium to long time rate of return.

However, the success factors of IT implementation cannot fully be defined and measured in economic terms. An alternative way to measure the success of IT implementation is to apply Benefits Realisation Management. This is an approach usually related to programme and project management, where strategic improvements in business value are called benefits. The creation of business value therefore depends strongly on programmes and projects delivering the expected benefits (Serra and Kunc, 2015). 


\section{Methodology}

The research studied four different organisations to answer the research question: How is environmental building performance managed through various IT systems, and are there any gaps between theoretical environmental indicators and those used in practice?

The research applied a maximum variance case study approach for collecting the empirical data to describe and explain the key themes that could be observed (Saunders et al., 2016). The maximum variance case study approach was selected as a research method for generalisation of results from practice (Flyvbjerg, 2006). Furthermore, the case study approach followed the general guidelines by Yin (2014) and Miles et al (2014) for delivering new knowledge from practice.

In maximum variation case studies, Patton (2002) suggests identifying different characteristics (sample selection criteria) before selecting the sample. The selection criteria in this research were organisational type and portfolio size. The studied organisations had different organisational type (governmental, public, private, educational) and portfolio size (between 105.000 and $4.000 .000 \mathrm{~m}^{2}$ ). The studied organisations were: The Danish Building and Property Agency (in Danish, Bygningsstyrelsen or BYGST), the national postal company Postnord Denmark, the private IT company KMD, and the educational institution Anglia Ruskin University from United Kingdom. The first author is industrial $\mathrm{PhD}$ fellow affiliated with the IT company KMD, which provides IT solutions on the Danish FM market, and has as such gained access to the selected organisations in Denmark.

The primary data source for case studies were semi-structured interviews. The interviews were based on open interview questions prepared in advance and outlined in an interview guide (Kvale and Brinkmann, 2015). The same interview guide was used for all interview sessions for easier comparison of the results between interviewees (within and across the organisations). The interview guide had fixed themes regarding interviewee background, organisation type and history, FM department, IT systems and FM data, while the interview questions were more flexible and could be slightly changed during the interview sessions, depending on the interview progress.

In total, eight interviews were conducted in the period May 2017 - April 2018 and they are listed in Table 1. The interviews provided important knowledge on the IT context in different organisations, drivers for implementing new IT systems, and on the organisational roles for managing EBP in practice. 


\begin{tabular}{|c|c|c|c|c|}
\hline $\begin{array}{l}\text { Case study } \\
\text { (organisation) }\end{array}$ & Interviewee & Business area & $\begin{array}{c}\text { Interview } \\
\text { date }\end{array}$ & $\begin{array}{c}\text { Interview } \\
\text { duration }\end{array}$ \\
\hline \multirow{3}{*}{$\begin{array}{l}\text { BYGST (governmental } \\
\text { real estate agency, DK) }\end{array}$} & Technical consultant & Energy management & $06-06-2017$ & $0: 53: 34$ \\
\hline & Head of IT dept. & IT systems and data & $16-08-2017$ & $0: 56: 56$ \\
\hline & Head of Building dept. & $\begin{array}{l}\text { Operation and maintenance } \\
\text { Construction projects }\end{array}$ & $18-08-2017$ & $1: 18: 43$ \\
\hline $\begin{array}{l}\text { Postnord Denmark } \\
\text { (public postal } \\
\text { company, DK) }\end{array}$ & FM specialist & $\begin{array}{l}\text { Operation and maintenance } \\
\text { Facilities management }\end{array}$ & $07-11-2017$ & $1: 02: 35$ \\
\hline \multirow{2}{*}{$\begin{array}{l}\text { KMD } \\
\text { (private IT company, } \\
\text { DK) }\end{array}$} & Head of FM dept. & $\begin{array}{l}\text { Facilities management } \\
\text { Hard FM }\end{array}$ & $14-09-2017$ & $0: 48: 34$ \\
\hline & FM director & $\begin{array}{l}\text { Facilities management } \\
\text { Hard and soft FM }\end{array}$ & $31-10-2017$ & $1: 00: 13$ \\
\hline \multirow{2}{*}{$\begin{array}{l}\text { Anglia Ruskin } \\
\text { University } \\
\text { (educational institution, } \\
\text { UK) }\end{array}$} & Sustainability engineer & $\begin{array}{l}\text { Operation and maintenance } \\
\text { BMS }\end{array}$ & 04-2018 & $1: 48: 59$ \\
\hline & Environmental manager & $\begin{array}{l}\text { Environmental sustainability } \\
\text { CSR reporting }\end{array}$ & $04-2018$ & $0: 43: 54$ \\
\hline
\end{tabular}

Table 1: Overview of interviews.

During the study of BYGST, five interviews were conducted, but only three interviews are included in this study, since they relate specifically to EBP. The interviews with Danish organisations were originally conducted in Danish and were later translated to English by the authors.

In two cases (BYGST and KMD), besides interviews, additional research data was collected through field observations and in-depth document studies. Field observations included participation in 8 implementation meetings (BYGST $=6 ; \mathrm{KMD}=2$ ), 4 workshops (BYGST) and 9 observation days during the IT implementations (BYGST $=7 ; \mathrm{KMD}=2$ ). In-depth document studies covered background material on the organisations and their business areas, FM departments, and system design documents. In field observations, research data included meeting minutes, personal notes and photos from the meetings and workshops.

\section{Findings}

\subsection{Case presentations}

The research studied four organisations with different organisation type and portfolio size to determine how they manage environmental building performance through IT systems. The following section provides more details about the organisations studied and presents findings from the study.

\subsubsection{The Danish Building and Property Agency (BYGST)}

The Danish Building and Property Agency (BYGST) was established in 2011 by merging former separate state agencies and has more than 300 employees today. BYGST is responsible for managing approx. $4.000 .000 \mathrm{~m}^{2}$ governmental buildings that are categorized in three groups: universities $(1,9$ mill. $\left.\mathrm{m}^{2}\right)$, office buildings $\left(0,9\right.$ mill. $\left.\mathrm{m}^{2}\right)$, and private leases $\left(1,2\right.$ mill. $\left.\mathrm{m}^{2}\right)$, which are rented out by BYGST and later sub-rented to its tenants such as ministries, governmental agencies, police, courts etc. The agency is currently undergoing the change management process to transform its silo-based organisation into a data-driven knowledge organisation. Relating to that, BYGST has decided to implement IWMS and EMS to ensure standardisation of core building data and business processes across the entire organisation. 


\subsubsection{Postnord Denmark}

Postnord Denmark (DK) provides postal services to households and businesses in Denmark. Postnord DK had 9.313 employees at the end of 2016. Due to decreasing postal demand in Denmark, Postnord DK has had several reorganisations and employment reductions over the past years. Consequently, the property portfolio has also been reduced from $650.000 \mathrm{~m}^{2}$ (in 2012) to approx. $600.000 \mathrm{~m}^{2}$ (in 2017), and the space optimisation process is still ongoing. All FM related tasks are outsourced to an external service provider, and Postnord DK only has one employee responsible for communication and coordination with external FM service provider. Postnord DK is a part of the Nordic postal consortium "Postnord" that also has branches in Finland, Norway and Sweden.

\subsubsection{KMD}

KMD is the largest IT company in Denmark and has more than 3.200 employees. KMD provides IT services primarily to Danish public organisations, but has also customers in the private sector, both domestically and in Sweden and Norway. KMD has departments in the four largest cities in Denmark and its building portfolio covers the total area of approx. $105.000 \mathrm{~m}^{2}$. In 2016, KMD had a large reorganisation of the FM department and reduced the number of employees from 28 to 16 . The new FM organisation is now divided in Hard and Soft service departments. The hard FM department is responsible for operation and maintenance of office and production (IT-server) buildings and handyman tasks. The soft FM department is responsible for cleaning, reception, canteen, travel arrangements and administration. The amount of FM service providers was also reduced from 78 (with and without service agreements) to 16 with service agreements. The new FM service providers are national and thus able to deliver service at all KMD locations. In relation to the recent FM reorganisation, it has been decided to implement IWMS and EMS to support the change process and strengthen the new, more centralised FM organisation.

\subsubsection{Anglia Ruskin University}

Anglia Ruskin University (ARU) is an educational institution in United Kingdom. The university has around 18.000 students and 1.800 staff members at three main campuses in UK: Chelmsford, Cambridge, and Peterborough. The university has 191 buildings covering $93.000 \mathrm{~m}^{2}$ of academic floorspace and $26.000 \mathrm{~m}^{2}$ of residential floorspace. 


\subsection{IT systems, their features, and user groups}

For comparing IT systems used for managing EBP in selected organisations, an overview of the crossanalysis of previously described cases is shown in Table 2. The analysis reveals similarities and differences across different organisations when it comes to their usage of IT systems in relation to FM and EBP.

\begin{tabular}{|c|c|c|c|c|}
\hline & $\begin{array}{l}\text { BYGST } \\
\text { (DK) }\end{array}$ & $\begin{array}{l}\text { Postnord Denmark } \\
\text { (DK) }\end{array}$ & $\begin{array}{l}\text { KMD } \\
\text { (DK) }\end{array}$ & $\begin{array}{c}\text { Anglia Ruskin } \\
\text { University } \\
\text { (UK) }\end{array}$ \\
\hline Organisation type & $\begin{array}{l}\text { Governmental } \\
\text { real estate agency }\end{array}$ & $\begin{array}{l}\text { Public postal } \\
\text { company }\end{array}$ & Private IT company & $\begin{array}{l}\text { Educational } \\
\text { institution }\end{array}$ \\
\hline Portfolio size $\left(\mathrm{m}^{2}\right)$ & 4.000 .000 & 600.000 & 105.000 & 119.000 \\
\hline Main IT system(s) & $\begin{array}{c}\text { EMS } \\
\left(\text { IWMS }^{*}\right)\end{array}$ & EMS & $\begin{array}{l}\text { MS Excel } \\
\text { BMS } \\
\left(\text { EMS }^{*}\right)\end{array}$ & $\begin{array}{l}\text { BMS } \\
\text { EMS } \\
\text { CAFM }\end{array}$ \\
\hline Features & $\begin{array}{l}\text { Energy management } \\
\text { Benchmarking }\end{array}$ & $\begin{array}{l}\text { Energy management } \\
\text { Benchmarking }\end{array}$ & $\begin{array}{l}\text { Energy reporting } \\
\text { Benchmarking }\end{array}$ & $\begin{array}{c}\text { Energy } \\
\text { management } \\
\text { Indoor climate }\end{array}$ \\
\hline KPIs & $\begin{array}{c}\text { Consumption } \\
\text { (hourly) } \\
\begin{array}{c}\text { Consumption vs. } \\
\text { budget }\end{array} \\
\text { Benchmarking }\left(\mathrm{m}^{2}\right) \\
\text { Degree-day adjustment } \\
\text { Emissions reporting }\end{array}$ & $\begin{array}{c}\text { Consumption } \\
\text { (hourly) } \\
\text { Consumption vs. } \\
\text { budget } \\
\text { Benchmarking }\left(\mathrm{m}^{2}\right)\end{array}$ & $\begin{array}{c}\text { Consumption } \\
\text { (monthly) } \\
\text { Benchmarking } \\
\text { (location, use type) }\end{array}$ & $\begin{array}{c}\text { Consumption } \\
(1 / 2 \text { hour })\end{array}$ \\
\hline User groups & $\begin{array}{l}\text { Energy managers } \\
\text { Facilities managers } \\
\text { Other employees } \\
\text { External users - } \\
\text { Tenants } \\
\end{array}$ & $\begin{array}{c}\text { Facilities managers } \\
\text { CSR dept. }\end{array}$ & $\begin{array}{c}\text { Facilities managers } \\
\text { CSR dept. }\end{array}$ & $\begin{array}{l}\text { Facilities man. } \\
\text { Sustainability eng. } \\
\text { Environment man. } \\
\text { CSR dept. }\end{array}$ \\
\hline
\end{tabular}

Table 2: Cross-analysis of cases.

*Onqoina implementation.

The portfolio size in the selected cases ranges between 105.000 and $4.000 .000 \mathrm{~m}^{2}$, and the analysis shows that the organisations use different IT systems to manage their facilities and EBP. According to their features, the systems can be grouped in three main categories: simple systems (like Excel), single point systems (BMS and EMS), and cross-functional systems (CAFM and IWMS).

Two organisations (BYGST and Postnord DK) use EMS for managing EBP, while the two other organisations (KMD and Anglia Ruskin) use combinations of several IT systems to manage EBP. BYGST is currently developing an interface between EMS and IWMS and plans also to use IWMS for strategic reporting of EBP. KMD has been using Microsoft Excel and combined it with BMS over several years to manage EBP, but the organisation is now in the process of implementing EMS. ARU uses BMS, EMS and CAFM to manage EBP on different organisational levels.

The identified IT systems are mainly used for energy management and benchmarking, with different degree of system functionality and data resolution across organisations. For example, KMD uses 
Microsoft Excel and BMS for manual reporting and benchmarking of aggregated (monthly) energy consumption across building locations (four cities) and use type (office space, print centre, data centre)(interview, FM director).

Contrary to KMD, Postnord DK performs similar tasks by using EMS. The EMS solution at Postnord DK automatically provides high-resolution (hourly) consumption data, which is used for energy reporting and benchmarking across the building portfolio and the use type (e.g. office space, production line etc.).

BYGST also uses EMS for automatic monitoring of hourly energy consumption across its office buildings and to benchmark the actual energy consumption with expected energy consumption based on the last year's consumption. Moreover, the EMS at BYGST and Postnord DK is used for adjusting the heating consumption demand according to weather conditions (degree-day adjustments) and for calculating GHG emissions based on the actual consumption (interview, technical consultant).

ARU uses BMS, EMS and CAFM for monitoring hourly energy consumption and for GHG reporting. At ARU, the EMS is used as energy metering system for benchmarking building performance and for bill validation. The electricity and gas data are sent every $1 / 2$ hour from BMS to EMS and the readings are presented in an energy dashboard tool. The water consumption is reported on higher level, i.e. with lower data resolution. The data resolution seems to have close ties with the financial value of each consumption type. The energy consumption (electricity and heating) at ARU was estimated to 2.2 million $£ / y r$. while water consumption was estimated to $100.000 £ / y r$. According to the environmental manager, these financial costs are the main reason why the focus is on energy, and less on water consumption.

Several user groups can be linked with the identified IT systems. The main users of EMS are energy specialists such as energy managers, facilities managers, energy consultants and CSR departments that require insight into high-resolution data on building energy performance. EMS can also provide access to the end-users (e.g. tenants) through an add-on web-service solution, so they can monitor their individual energy consumption and compare it with the planned consumption. BMS is primarily used by the technicians and mechanical engineers to monitor HVAC's technical performance. IWMS, in combination with EMS, can be used to consolidate energy data with other building-related data to create new KPIs and dashboards on building performance. These IWMS features can be useful for top managers for strategic reporting on EBP. Also CAFM can be used for this purpose, but depending on its configuration, CAFM might have limited cross-functionality features when compared with IWMS.

The interviews and the cross-case analysis disclose different incentives to reduce environmental impacts from building operation. For example, BYGST provides web access to energy consumption for each tenant, enabling the tenants to follow and analyse their individual energy consumption. Based on the consumption data, BYGST also provides energy consulting to the tenants, guiding them how to save energy, as a part of national strategy on reducing energy consumption in governmental buildings. Postnord DK uses EMS for benchmarking energy consumption and running internal green campaigns, raising the awareness of energy consumption in their buildings, as well as encouraging the employees across the country to compete in delivering the biggest energy savings. 


\subsection{IT systems and environmental building performance}

The more comprehensive analysis of IT systems and their features on different environmental categories is presented in Table 3. All four organisations use IT systems to report and benchmark energy, water and GHG emissions on different levels. The organisations also collect data on waste from different external sources for reporting purposes, but these data are not stored in the studied systems. KMD and ARU, both ISO 14001 certified, also collect data on reuse potentials for some specific topics like hazardous materials and waste recycling. Indoor environmental quality (IEQ) is partially covered through BMS, while the remaining environmental categories are not managed through the studied IT systems.

\begin{tabular}{|l|c|c|c|c|}
\hline & BYGST & KMD & $\begin{array}{c}\text { Postnord } \\
\text { Denmark }\end{array}$ & $\begin{array}{c}\text { Anglia Ruskin } \\
\text { University }\end{array}$ \\
\hline Organisation type & $\begin{array}{c}\text { Governmental } \\
\text { real estate agency }\end{array}$ & $\begin{array}{c}\text { Private IT } \\
\text { company }\end{array}$ & $\begin{array}{c}\text { Public postal } \\
\text { company }\end{array}$ & $\begin{array}{c}\text { Educational } \\
\text { institution }\end{array}$ \\
\hline Portfolio size (m ${ }^{2}$ ) & 4.000 .000 & 105.000 & 600.000 & 119.000 \\
\hline Main IT system(s) for EBP & EMS & Excel & EMS & BMS \\
& IWMS* & BMS & CAFM \\
\hline Energy management & YES & YES & YES & YES \\
\hline Water management & YES & YES & YES & YES \\
\hline Emissions & YES & YES & YES & YES \\
\hline Waste management & (YES) & (YES) & NO & (YES) \\
\hline Space management & NO & NO & NO & NO \\
\hline Building materials & NO & NO & (YES - BMS) & (YES - BMS) \\
\hline Indoor environmental quality** & (YES - BMS) & (YES - BMS) & NO & (YES) \\
\hline Reuse potential & NO & (YES) & & \\
\hline
\end{tabular}

Table 3: Environmental categories covered by the IT systems.

*Ongoing implementation.

**IEQ category: Some indicators are monitored and reported on through BMS.

When it comes to energy and water management, all four organisations use IT systems to report and benchmark electricity, heating and water consumption. In Denmark, EMS seems to be the preferred IT system for this purpose. The reasons might be the system's connectivity with the consumption meters and the ability to collect the consumption data directly from the utility companies. For example, BYGST and Postnord DK automatically receive hourly data on electricity, heating and water consumption to EMS directly from their consumption meters. Moreover, EMS also includes additional features on energy management such as water flow, heating efficiency, volume etc., but these features depend on the technical characteristics of each consumption meter. As observed at BYGST, managing EBP through IT systems can be further supported with IWMS, where consumption data from EMS is combined with building-related data to create new insights on energy management and real estate management.

The organisations without EMS seem to use BMS and combine it with other IT systems to manage EBP. KMD has been using Excel during ten years for energy reporting and benchmarking, demonstrating that also simple IT systems can be used for energy management to a certain level. 
KMD collected the consumption data in Excel partly through remote readings in BMS, and mostly through manual consumption readings on all locations (interview, FM director). However, this manual data collection process included the risk of consumption misreading and typing errors in Excel, since the system itself did not contain any data validation features. Due to the recent FM reorganisation and reduced number of FM employees, KMD has now decided to automatize data collection process and ensure data validity by implementing EMS.

Anglia Ruskin University uses BMS and EMS for energy management and combines the data with CAFM to provide deeper insights on EBP. In this case, BMS is used by a sustainability engineer for monitoring HVAC installations and their energy performance. EMS is used by an environmental manager. However, the BMS system lacks important notification features on inadequate indoor temperature, which often leads to reactive maintenance rather than preventive actions. The BMS is also rarely maintained due to few human resources, leading to reduced system functionality and questioning data validity (interview, sustainability engineer).

Besides energy and water management, IT systems like EMS, CAFM and IWMS can be used to calculate and report GHG emissions. The calculated emissions are typically based on the actual energy consumption, which later is converted into GHG emissions through the standardisation factors included in the software or defined by the users. The reporting format is typically $\mathrm{CO}_{2}$ or $\mathrm{CO}_{2 \mathrm{e}}$ in kilograms.

An in-depth study of the identified systems showed that they contain additional functionalities related to EBP, but that these are not used in practice. For example, EMS can offer waste management, but none of the studied organisations was using this functionality. IWMS and CAFM include space management features that can visualise how the building areas are being utilised, but also this functionality was not in use in any of the studied organisations. On the other hand, the study disclosed that data and functionalities related to building materials, their properties and maintenance, as well as the reuse potential of building components were missing in the examined IT systems.

Regarding indoor environmental quality, some indicators related to energy like indoor temperature, air quality and relative humidity can be monitored and reported through BMS. It is however different, how the studied organisations manage IEQ in practice, since their building portfolios contain many different buildings with varying age, use type and technical conditions (e.g. natural or mechanical ventilation), which leads to a disperse picture on IEQ performance. The systems like EMS, CAFM and IWMS do not seem to offer deeper insight into IEQ but appear to be solely focusing on reporting and benchmarking energy consumption, while BMS covers the technical aspects of HVAC installations and hereby partially covers IEQ indicators.

\section{Discussion}

The article studied how environmental building performance is managed through various IT systems by applying maximum variance case study approach. This methodology was chosen for generalisation of results and delivering new knowledge from the practice. Thus, the selected cases provide general overview of the current situation and do not reflect in-depth studies of each sector. The selected Danish cases were all accessed through KMD, providing unique insight into their IT systems and organisations, but this approach also limited the access to other organisations using competing systems. 
The study found that IT systems used for managing EBP can range from simple systems like MS Excel, single point systems like BMS and EMS, till more complex, cross-functional systems like CAFM and IWMS. The system type used in different organisations seems to be determined by the benefits each IT system can bring to an organisation and the organisational needs on environmental performance reporting. All studied organisations use IT systems to monitor and benchmark energy and water consumption, categories that beside environmental impacts also have large impacts on operational costs and the financial bottom line. These findings are in line with earlier findings (Barkley, 2011; DFM, 2018a), claiming that IT systems are used for reporting, planning and decision support. However, the organisational approach to energy and water management varies greatly. As illustrated in case studies, some organisations collect the data manually and monitor energy consumption on a monthly basis, while other organisations require automated, detailed, hourly reporting, leading to different possibilities in data analytics. Having access to high-resolution (hourly) consumption data can visualise not only energy consumption, but for example also show how the consumption is distributed between working hours, non-working hours and during weekends, and enable new benchmarking possibilities. Moreover, the automatic data processing systems like EMS should be preferred, since they can release valuable human resources and reduce the risk of misreading and typing errors when using manual readings.

The cross-case analysis indicates two general IT models for managing EBP: one based on EMS and its add-ons, other on BMS and its add-on solutions. The main differences between the two models are presented in Table 4.

\begin{tabular}{|l|l|l|}
\hline & \multicolumn{1}{|c|}{ BMS } & \multicolumn{1}{|c|}{ EMS } \\
\hline System type & Single point & Single point \\
\hline Data source(s) & $\begin{array}{l}\text { Technical installations (HVAC) } \\
\text { Sensors }\end{array}$ & Consumption meters \\
\hline Data capture method & $\begin{array}{l}\text { Automatic } \\
\text { Manual }\end{array}$ & Automatic \\
\hline Data processing & Mostly manual & Automatic \\
\hline Key features & $\begin{array}{l}\text { Indoor comfort (temperature) } \\
\text { Air quality } \\
\text { Ventilation frequency }\end{array}$ & $\begin{array}{l}\text { Electricity consumption } \\
\text { Heating consumption } \\
\text { Water consumption }\end{array}$ \\
\hline Typical users & $\begin{array}{l}\text { Technicians } \\
\text { Facilities managers }\end{array}$ & $\begin{array}{l}\text { Energy managers } \\
\text { Facilities managers } \\
\text { Utility companies } \\
\text { End-users (through web-tools) }\end{array}$ \\
\hline
\end{tabular}

Table 4: The BMS and EMS models as observed through the cases.

Ebbesen (2016) characterised both BMS and EMS as "Facilities Intelligence Systems", and our case studies showed that also "Workflow Systems" CAFM and IWMS can be used to manage EBP. In Denmark, the EMS model seems to be the dominating model for managing EBP. EMS is used for automatic collecting of hourly consumption data and can be used as a stand-alone solution or combined with other IT systems. The BMS model was observed at ARU, and it showed similarities with the system configuration used in one Danish case (KMD - now implementing EMS). The BMS 
model relies mainly on the performance data from HVAC, which later are manually processed, either by use of a specific BMS software or other IT systems, like Excel or even EMS.

The BMS and EMS models focus on energy performance through different approaches. While the EMS model is based on collecting the consumption data from consumption meters and used for automated monitoring of energy consumption across building portfolio, the BMS model is more technical, focused on specific HVAC installations, and therefore has more measuring points within each building compared to EMS model.

The findings from this research indicate a transition towards EMS models and more automated data collection. However, it must be pointed out that the BMS model should not be perceived as an opponent to EMS model, but more as an important supplementary model. The BMS model contains valuable data on indoor climate and buildings' technical performance, which are not included in the EMS model, but are very important for users' comfort and productivity, as well as for EBP.

The study showed, when using the IT, the data source and data harvesting are important parameters. To collect consumption data in EMS, the utility company must be willing to provide the data into the system, even though the data concerns your own facilities. This raises several questions concerning data ownership (Who owns the data?), data management (How much data can utility company provide? Which data: only consumption, or also other measuring points?), data accessibility (Who should have access to your data?), exchange standards (Data format between utility company and EMS) etc., which not only relate to building owners, users/tenants and FM organisations, but also involve other external stakeholders like software developers, utility companies and legislators.

Another important subject regarding data collection in EMS is the technical aspect of consumption meters. The consumption data are delivered to EMS through remote readings. It means that the consumption meters must be digital and able to support remote readings for delivering data to EMS. However, the picture is very diversified when it comes to meter maturity of different consumption types. In Denmark, the electricity meters are most matured and support high-resolution data reporting (nowadays down to 5 minutes intervals), and there is a national data hub in which all electricity consumption data are stored. The utility companies provide data to the data hub, and the personal consumption data can be accessed through web access. The heating meters are also very mature, but not all heating suppliers are currently able to provide hourly data, and there is no national heating data hub. Water consumption data are most difficult to collect as there are still many manual meters, meaning that the water consumption is not as easy to monitor and benchmark as electricity and heating consumption. This meter/data issue was recently also highlighted by BYGST showing that $95 \%$ of electricity, $65 \%$ of heating, and only $35 \%$ of water consumption in their office buildings was automatically reported to EMS (Bygningsstyrelsen, 2017). The digitisation of consumption meters is still ongoing, so it is the matter of time until more consumption data can automatically be collected and managed in EMS.

None of the four cases included examples of attempts to measure the success of IT implementation in economic terms. However, in the IT implementation at BYGST, a benefits realisation framework was applied. The benefit realisation diagram for energy management at BYGST is shown in Anonymous (2018). 
The results can be used to support decision-making in organisations, who want to improve the environmental building performance in facilities management by implementing new and developing existing IT systems. The case studies can be used for inspiration in the preparation of such decisions.

\section{Conclusion}

Environmental building performance can be managed through three types of IT systems: simple systems, single point systems, and cross-functional systems. There is a great variance how these IT systems are used for managing EBP in practice, and to which extent they cover different environmental categories.

There are two dominating models for managing EBP through IT systems: EMS and BMS. The two models do not necessarily exclude each other and can be used supplementary. The EMS model appears to be the leading model for managing EBP in Denmark. It focuses on monitoring and benchmarking energy and water consumption and can also be used for waste management. The key benefit of the EMS model is that it automatically collects consumption data through remote meter readings and can manage high-resolution data collection.

Companies not using EMS can use BMS and combine it with other systems to manage EBP. The BMS model requires more human resources since the data management is less automated compared to EMS, including higher risk of incorrect consumption data. On the other hand, BMS provides important data on indoor environmental quality, a feature that EMS lacks, and the BMS model should therefore be considered as a supplement to EMS.

The IT systems are mostly used for energy and water management, and for reporting GHG emissions. Some IT systems offer additional features related to EBP like waste management and space management, but these features were not in use by the case organisations in this study. On the other hand, IT systems lack features on building materials and reuse potential. The management of indoor environmental quality is partially supported through BMS, but rarely linked with other environmental categories. Deeper interaction of BMS with EMS, combined with interfacing with workflow systems like CAFM and IWMS might improve management of environmental building performance and provide more comprehensive picture of environmental sustainability within building portfolio.

This research mainly relates to the Danish FM context and IT systems provided or related to the IT company KMD. As such, the results might be biased or limited, and there is therefore need for further research within this field. The authors suggest research on how FM organisations outside of Denmark use IT systems for managing EBP, what their organisational drivers and needs are, as well as determining which benefits IT systems bring to different stakeholders in relation to environmental sustainability. Moreover, there is also a need for comparative studies of organisations using BMS and EMS, to determine in which way these systems support EBP and how they can be combined.

\section{Acknowledgements}

This research is a part of industrial $\mathrm{PhD}$ project founded by the IT company KMD and Innovation Fund Denmark (5016-00174B). The authors would like to thank Bygningsstyrelsen, KMD, Postnord Denmark and Anglia Ruskin University for allowing the authors to study their organisations and IT systems. 


\section{References}

Anonymous (2018) - conference paper. Reference anonymised for review.

Alvesson, M. and Kärreman, D. (2001), "Odd couple: making sense of the curios concept of knowledge management", Journal of Management Studies, 38(7), pp. 995-1018.

Barkley, L. (2001) "Key performance indicators: Primary drivers of information systems design", Journal of Corporate Real Estate, 3(2), pp.161-171.

Bygningsstyrelsen (2017) Hurtigere og bedre energidata til ministerier, styrelser og andre statslige institutioner. Available at: https://www. bygst.dk/nyt-og-presse/nyhedsarkiv/hurtigere-og-bedreenergidata-til-ministerier,-styrelser-og-andre-statslige-institutioner/ (Accessed: 22 February 2018).

Cabeza, L. F., Rincón, L., Vilariño, V., Pérez, G., Castell, A. (2014) 'Life cycle assessment (LCA) and life cycle energy analysis (LCEA) of buildings and the building sector: A review', Renewable and Sustainable Energy Reviews, 29, pp. 394-416.

Davenport, T. H., Long, D. W. De and Beers, M. C. (1998) 'Successful Knowledge Management Projects', MIT Sloan Management Review, 39(2), pp. 43-57.

DFM (2018a) 'Facilities Management som digital forandringsagent', Danish FM Association, book.

DFM (2018b) 'FM systemer i Danmark'. Available at: https://www.dfm-

net.dk/images/sider/fm_systemer/FM-systemer_i_Danmark_2018_og_cases_fra_2017_-_iPaper.pdf (Accessed: 18 August 2019).

Dubey, K. K. and Kalwale, D. (2010) 'Knowledge Management: An Overview', in Conference Proceedings, ICWET International Conference and Workshop on Emerging Trends in Technology, Mumbai, India, pp. 565-568.

Eastman, C., Teicholz, P., Sacks, R., Liston, K. (2008) BIM Handbook: A Guide to Building Information Modeling for Owners, Managers, Designers, Engineers, and Contractors. John Wiley \& Sons, Inc.

Ebbesen, P. (2015) 'Information Technology in Facilities Management - A Literature Review', in Alexander, K. and Price, I. (eds) Advancing Knowledge in Facilities Management: People make Facilities Management. EuroFM., pp. 1-14.

Ebbesen, P. (2016) Adding Value to Facilities Management with Information Technology. PhD dissertation. DTU Management.

Elmualim, A. and Pelumi-Johnson, A. (2009) 'Application of computer-aided facilities management (CAFM) for intelligent buildings operation', Facilities, 27(11-12), pp. 421-428.

Flyvbjerg, B. (2006) 'Five Misunderstandings About Case-Study Research', Qualitative Inquiry, 12(2) pp. 219-245. Sage Publications.

García-Sánchez, N. and Pérez-Bernal, L. E. (2007) 'Determination of critical success factors in implementing an ERP system: A field study in Mexican enterprises', Information Technology for Development, 13(3), pp. 293-309.

GEFMA (2017) Marktübersicht CAFM-Software. Implementierung und Datenerfasssung. Report. GEFMA 940, Germany.

Gibler, K. M., Gibler, R. R. and Anderson, D. (2010) 'Evaluating corporate real estate management decision support software solutions', Journal of Corporate Real Estate, 12(2), pp. 117-134. 
Hanley, B. P. and Brake, D. J. (2016) 'Putting asset data at the heart of organisational decision-making using an Integrated Workplace Management System', in Asset Management Conference, pp. 1-7.

Heisig, P. (2009), "Harmonisation of knowledge management - comparing 160KM frameworks around the globe", Journal of Knowledge Management, 13(4), pp. 4-31.

International Energy Agency (2017) Energy Technology Perspectives 2017. Available at: https://www.iea.org/buildings/.

Kvale, S. and Brinkmann, S. (2015) 'Interview - det kvalitative forskningsinterview som håndværk'. Third edition. HansReitzels.

Lewis, A., Riley, D. and Elmualim, A. (2010) ‘Defining High Performance Buildings for Operations and Maintenance', International Journal of Facility Management, 1(2), pp. 1-16.

Lundvall, B. (2004), "The economics of knowledge and learning", in Christensen, J. and Lundvall, B. (Eds), Product Innovation, Interactive Learning and Economic Performance (Research on Technological Innovation, Management and Policy), 1st ed., Emerald, Bingley, pp. 21-42.

Madritsch, T. and May, M. (2009) 'Successful IT implementation in facility management', Facilities, 27(11/12), pp. 429-444.

Maslesa, E., Jensen, P. A. and Birkved, M. (2018) 'Indicators for quantifying environmental building performance: A systematic literature review', Journal of Building Engineering, pp. 552-560.

McBeath, A. and Ball, P. (2012), "Towards a framework for transferring technology knowledge between facilities", Strategic Outsourcing: An International Journal, 5(3), pp. 213-231.

Miles, M. B., Hubermann, A. M. and Saldana, J. (2014) 'Qualitative Data Analysis - A Methods Sourcebook'. Third edition. SAGE Publications.

Mutalib, A. F. A., Sapri, M. and Sipan, I. (2018) 'An assessment model for FM performance', Facilities, 36(3/4), pp. 212-226.

Pan, S.L. and Scarbrough, H. (1999), "Knowledge management in practise: 'an exploratory case study", Technology Analysis and Strategic Management, 11(3), pp. 359-374.

Pathirage, C., Haigh, R., Amaratunga, D. and Baldry, D. (2008) 'Knowledge management practices in facility organisations: a case study', Journal of Facilities Management, 6(1), pp. 5-22.

Patton, M. Q. (2002) ' Qualitative Research \& Evaluation Methods'. Third Edition. Sage Publications.

Prischl, P., Hohmann, J., Koch, S., Quadt, M. and Ritter, T. (2012) 'Economic Benefits of a CAFM Implementation', in May, M. and Williams, G. (eds) The Facility Manager's Guide to Information Technology. IFMA Technology Council and GEFMA.

Pärn, E. A., Edwards, D. J. and Sing, M. C. P. (2017) 'The building information modelling trajectory in facilities management: A review', Automation in Construction, 75, pp. 45-55.

Saunders, M., Lewis, P. and Thornhill, A. (2016) Research methods for business students. Seventh edition. Pearson.

Serra, C. E. M. and Kunc, M. (2015) 'Benefits Realisation Management and its influence on project success and on the execution of business strategies', International Journal of Project Management, 33(1), pp. 5366. 
Sharma, A., Saxena, A., Sethi, M., Shree, V. (2011) 'Life cycle assessment of buildings: A review', Renewable and Sustainable Energy Reviews, 15(1), pp. 871-875.

Smith, E. A. (2001) 'The role of tacit and explicit knowledge in the workplace', Journal of Knowledge Management, 5(4), pp. 311-321.

Trimble (2018) Trimble Manhattan - Plan, Manage and Optimize your Real Estate and Workplace Portfolio. Available at: https://realestate.trimble.com/products/manhattan/ (Accessed: 10 December 2018).

Vianello, G. and Ahmed-Kristensen, S. (2012), "Transfer of knowledge from the service phase: a case study from the oil industry", Research in Engineering Design, 23(2), pp. 125-139.

Yin, R. K. (2014) Case Study Research. Fifth edition. SAGE Publications. 